\title{
Atuação do psicólogo escolar na rede pública de ensino: Concepções e práticas
}

\author{
Performance of the pertaining to school psychologist in the public net of education: \\ Practical and conceptions
}

\section{Lucilaide Galdino de Medeiros ${ }^{[a]}$, Fabíola de Sousa Braz Aquino ${ }^{[b]}$}

[a] Graduada em Psicologia pela Universidade Estadual da Paraíba (UEPB), Campina Grande, PB - Brasil, e-mail: lucilaidemed@gmail.com

[b] Professora do Departamento de Psicologia da Universidade Estadual da Paraíba (UEPB) e Doutora em Psicologia Social pelo Programa Integrado de Pós-Graduação em Psicologia Social (UFPB/UFRN), João Pessoa, PB - Brasil.

\section{Resumo}

A escola é um dos campos de reflexão e intervenção do psicólogo escolar. A construção de pesquisas e reflexões sobre esse campo de atuação parece importante, necessariamente, pela contribuição ao debate estabelecido entre psicologia e educação, e por permitir revelar contribuições para consolidar a atuação profissional nesse contexto da instituição escolar. O presente estudo buscou conhecer e discutir a atuação de psicólogos em escolas públicas da cidade de Campina Grande, PB. Os dados foram coletados por meio de uma entrevista semiestruturada aplicada a sete psicólogos escolares. Os resultados demonstraram que os psicólogos concebem suas atividades como diversificadas, envolvendo alunos, professores e família. No entanto, vale destacar a desarticulação existente entre teoria e prática profissional, o que pode ser observado no distanciamento entre o que os psicólogos relatam como sendo seu papel e a sua prática profissional. O trabalho interdisciplinar foi destacado pelos psicólogos como importante para a prática profissional. Por outro lado, foram mencionadas dificuldades para a prática do psicólogo, tais como a de se fazer reconhecer pela comunidade escolar como detentor de contribuições relevantes para agir como mediador do processo educativo. Entende-se que essas contribuições somente poderão ser percebidas à medida que os profissionais conhecerem melhor suas possibilidades de atuação para intervir na comunidade escolar e ressignificar sua atuação profissional. Faz-se necessária ainda uma atuação contextualizada, na qual a psicologia possa mostrar suas contribuições no campo educativo.

Palavras-chave: Psicologia escolar. Escola pública. Atuação do psicólogo. 


\begin{abstract}
The school is one of the fields of reflection and intervention by the school psychologist. The construction of research and reflection on this field of action seems important, necessarily, the contribution to the debate established between psychology and education, and for allowing disclose contributions to consolidating the professional activity in this context of the school. this study sought to identify and discuss the role of psychologists in public schools in the city of Campina Grande, PB. Data were collected through a semi-structured interviews with seven school psychologists. The results demonstrated that psychologists perceive their activities as diverse, involving students, teachers and family. However, it is worth highlighting the disconnection between theory and practice, which can be observed in the gap between what psychologists describe as their role and professional practice. Interdisciplinary work was emphasized by psychologists with important for professional practice. On the other hand, were referred to practical difficulties such as the psychologist to seek recognition by the school community as having significant contributions to act as mediator in the educational process. It is understood that such contributions can only be perceived as professionals more aware of their possibilities of action to intervene in the school community and re-signify their professional activities. It is necessary also a performance in context, in which psychology can show their contributions in the educational field.
\end{abstract}

Keywords: School psychology. Public school. Psychologist's performance.

\section{Introduçáo}

A escola é um dos campos de reflexão e intervenção do psicólogo escolar e a construção de intervenções no processo educativo constitui uma das principais direções de trabalho na instituição escolar. Considerando o desenvolvimento atual da área de psicologia escolar no Brasil, parece importante a pesquisa e reflexão sobre esse campo de atuação, necessariamente pela contribuição ao debate estabelecido entre a psicologia e a educação, e por permitir revelar contribuições para consolidar a atuação profissional nesse contexto da instituição escolar.

A atuação do psicólogo escolar tem sido pauta em muitos debates no meio universitário. Segundo Guzzo (1996, p. 75), a legislação que respalda a psicologia como prática profissional e formação tem "características bem generalistas e responde pouco às demandas mais modernas da sociedade brasileira". Dessa forma, a psicologia escolar no Brasil tem percorrido uma história cheia de contradições e dificuldades, e ainda não há no país uma especificidade no título profissional, ou seja, não existe um modelo de atuação difundido e estudado, e isso dificulta uma prática competente no contexto educacional (Almeida, 2002; Guzzo, 1996; Correia, 2004).

A atuação inicial do psicólogo na escola era marcantemente focada no aluno, tendo como pressupostos modelos individualistas e uma atuação caracterizada por práticas remediativas, com predominância a tendências psicométricas apoiadas na aplicação de testes psicológicos (Almeida \& Marinho-Araújo, 2005; Andrada, 2005; Leite \& Valle, 2003).

As reflexões desses modelos de atuação desenvolvidas por pesquisadores no campo da psicologia escolar conduziram a muitas críticas, pois essas orientações pareciam não dar suporte as novas demandas encontradas no contexto educacional. As críticas surgidas a partir dessa forma de atuação, desencadearam mudanças na atuação profissional (Almeida, 2002). De acordo com Tanamachi \& Meira (2003, p. 15), o movimento de crítica pautouse pela "constatação e denúncia aos pressupostos teórico-práticos da psicologia e da educação e pelo diagnóstico e análise crítica da história da psicologia na educação". Na perspectiva desses mesmos autores, esse movimento exigia novos posicionamentos na atuação profissional do psicólogo.

Ao refletir sobre a atuação do psicólogo nas escolas, Almeida (2002) assinala que os posicionamentos em relação ao modelo clínico-terapêutico na escola tiveram grande pertinência, no entanto parece não ter oferecido aos psicólogos um modelo teórico que pudesse subsidiar a prática profissional. Essas questões assimiladas sem criticidade contribuíram para aprofundar a crise de identidade profissional e 
gerar uma perda de seu espaço de atuação. A falta de uma especificidade do trabalho do psicólogo no contexto educacional alargaria a fragilidade do perfil profissional e dificultaria uma atuação eficaz (Almeida, 2002; Guzzo 1996; Correia, 2004).

Vários autores (Correia, 2004; Guzzo, 1996; Martins, 2003; Almeida, 2002) discutem sobre as dificuldades encontradas pelos psicólogos para se inserirem no sistema escolar. Guzzo (1996) destaca a dificuldade de articular teoria e prática e a ausência de modelos para atuação profissional. Já Correia (2004) menciona que o conhecimento ou o "não conhecimento" da profissão do(a) psicólogo(a) pela comunidade escolaré considerado um grande desafio para atuação do psicólogo.

Um estudo, desenvolvido por Reis (2008), sobre a visão do psicólogo pelos profissionais e estudantes em uma instituição de ensino privada de Manaus mostrou que os alunos e profissionais da escola atribuem as atividades do psicólogo clínico ao psicólogo escolar, demonstrando que o papel do psicólogo ainda é percebido como restrito ao atendimento de alunos e da não interferência nas atividades de outros profissionais. Pode-se notar, portanto, que a representação do psicólogo na escola identificada é a de um profissional que exerce funções de ajuda.

A análise dessas questões discutidas anteriormente, como a atuação focada no modelo clínico terapêutico e a fragilidade do perfil profissional, produz discussões diversas no que diz respeito à elaboração de práticas críticas em psicologia escolar. Para Guzzo (1996, p. 87), as perspectivas em psicologia escolar no Brasil passam pela revisão da formação do psicólogo, "além de uma definição ampla e socializada sobre os padrões éticos e de qualidade no exercício profissional, defendidos por associações de classes científicas da área". Sendo assim, considera-se fundamental criar condições para avançar num processo de construção de conhecimentos teórico-críticos em psicologia escolar que faça viabilizar uma mediação entre as finalidades transformadoras da prática nessa área.

Tendo por base as contribuições da psicologia crítica, Almeida e Marinho-Araújo (2005, p. 86) consideram que a prática em psicologia escolar atual exige uma "práxis contextualizada e referendada no mundo do trabalho por pressupostos que permitam uma compreensão dialética da relação entre indivíduos, enquanto sujeitos de sua história, e o contexto sócio-cultural". Apesar de serem vastos os modelos de atuação, ainda não existe um modelo difundido para prática do psicólogo escolar. No entanto, encontram-se, na literatura da área, autores que discutem sobre a atuação desse profissional (Almeida \& Marinho-Araújo, 2005; Almeida \& Neves, 2003; Leite \& Valle, 2003; Martinez, 2003; Santos, 2004), bem como autores que estão preocupados em desenvolver práticas e discutir ações que venham a contribuir para o desenvolvimento de ações profissionais e colaborar com a consolidação da área em psicologia escolar.

$\mathrm{Na}$ literatura acerca da atuação do psicólogo escolar, podem-se encontrar trabalhos que discutem a atuação desse profissional enquanto educador (Almeida \& Neves, 2003; Santos, 2004; Martinez, 2003) ou como um profissional que desenvolve um trabalho interdisciplinar com ênfase nas relações interpessoais (Almeida, 2002; Andrada, 2005; Almeida \& Marinho-Araújo, 2005; Leite \& Valle, 2003; Martinez, 2003; Santos, 2004). O trabalho interdisciplinar abre espaço para o desenvolvimento de ações junto aos educadores e outros profissionais da escola, onde se podem criar espaços de diálogos para que os problemas vivenciados na instituição possam ser discutidos e compartilhados na busca de soluções e juntos possam estabelecer novas maneiras de olhar o aluno, evitando rótulos.

Ademais, a área de Psicologia Escolar tem desenvolvido nos últimos anos uma importante discussão em relação à atuação do psicólogo no campo educativo, em busca de perspectivas que superem modelos individualistas e médicos que permearam o campo educacional, o que reflete a tentativa de romper padrões tradicionais da teoria e prática profissional.

Considerando as questões supracitadas, este estudo tem como objetivo geral conhecer e discutir as formas de atuação de psicólogos de escolas públicas da cidade de Campina Grande, PB. Especificamente buscou-seidentificar os referenciais teóricos utilizados para orientar a prática profissional destes; caracterizar as concepções dos psicólogos acerca de sua atuação profissional nas escolas; verificar as situações nas quais ocorre o trabalho do psicólogo na instituição educacional; e descrever as intervenções dos psicólogos nas escolas públicas da cidade investigada. 


\section{Método}

\section{Sujeitos}

Participaram deste estudo sete psicólogos, de ambos os sexos, na faixa etária entre 35 e 48 anos, que trabalham na rede pública de ensino da cidade de Campina Grande, PB. A experiência na área de psicologia escolar dos sujeitos variou de 4 a 19 anos de exercício profissional. Para uma melhor caracterização da amostra, estão dispostos os dados sociodemográficos dos profissionais que participaram do presente estudo (Quadro 1).

Quadro 1 - Dados sociodemográficos dos psicólogos

\begin{tabular}{|c|c|c|c|c|c|c|}
\hline Profissionais & Sexo & $\begin{array}{l}\text { Idade } \\
\text { (anos) }\end{array}$ & $\begin{array}{l}\text { Nível de } \\
\text { instrução }\end{array}$ & $\begin{array}{l}\text { Tempo } \\
\text { atuação na } \\
\text { área (anos) }\end{array}$ & $\begin{array}{l}\text { Área de } \\
\text { supervisão }\end{array}$ & $\begin{array}{l}\text { Outra } \\
\text { experiência } \\
\text { profissional }\end{array}$ \\
\hline Psicólogo 1 & Feminino & 36 & $\begin{array}{l}\text { Especialista em } \\
\text { Psicologia da } \\
\text { Infância e da } \\
\text { Adolescência e em } \\
\text { Psicologia Social }\end{array}$ & 04 & Clínica analítica & Psicóloga clínica \\
\hline Psicólogo 2 & Feminino & 40 & $\begin{array}{l}\text { Especialista } \\
\text { em Psicologia } \\
\text { da Infância e } \\
\text { Adolescência }\end{array}$ & 06 & Clínica analítica & - \\
\hline Psicólogo 3 & Masculino & 35 & $\begin{array}{l}\text { Especialista em } \\
\text { Psicopedagogia }\end{array}$ & 04 & $\begin{array}{l}\text { Escolar/ } \\
\text { educacional }\end{array}$ & - \\
\hline Psicólogo 4 & Masculino & 57 & Graduação & 05 & Organizacional & - \\
\hline Psicólogo 5 & Feminino & 40 & $\begin{array}{l}\text { Especialista em } \\
\text { Psicopedagogia }\end{array}$ & 15 & $\begin{array}{l}\text { Clínica infantil/ } \\
\text { centrada }\end{array}$ & Psicóloga clínica \\
\hline Psicólogo 6 & Feminino & 47 & $\begin{array}{l}\text { Especialista em } \\
\text { Psicologia da } \\
\text { Personalidade e } \\
\text { Inclusão Escolar }\end{array}$ & 19 & Clínica analítica & $\begin{array}{l}\text { Coordenadora de } \\
\text { educação inclusiva } \\
\text { no município }\end{array}$ \\
\hline Psicólogo 7 & Feminino & 48 & $\begin{array}{l}\text { Especialista em } \\
\text { Gestão Educacional }\end{array}$ & 10 & $\begin{array}{l}\text { Escolar/ } \\
\text { educacional }\end{array}$ & $\begin{array}{l}\text { Professora de nível } \\
\text { superior }\end{array}$ \\
\hline
\end{tabular}

Material

Os dados foram obtidos por meio de entrevistas semiestruturadas, registradas em um minigravador e lápis e papel para transcrição.

\section{Procedimentos para coleta de dados}

Inicialmente a pesquisadora (primeira autora) entrou em contato com uma psicóloga escolar por meio de telefone. Esta, por sua vez, indicou o contato de outros colegas da área. Os demais contatos foram realizados na secretaria de educação do município, que forneceu nome e telefone de alguns psicólogos que atuam na rede municipal. Em relação às escolas estaduais procuradas, todas tinham psicólogos atuando, porém não foi conseguido contato com estes, inviabilizando a inclusão na pesquisa.

Após entrar em contato com cada profissional, foi marcado o dia e local para realização da entrevista. As entrevistas ocorreram na secretaria de educação da cidade de Campina Grande, nas escolas onde os profissionais atuam, foram realizadas em local estabelecido por sujeito e de forma individual.

No primeiro encontro com os profissionais, foram explicitados os objetivos da pesquisa e solicitado o consentimento para a realização dos registros 
em áudio. A inclusão dos participantes no estudo foi condicionada à leitura e assinatura do Termo de Compromisso Livre e Esclarecido.

A análise das falas dos psicólogos entrevistados baseou-se nas cinco questões que compuseram a entrevista, quais sejam: motivos que levaram o profissional a optar pela área de psicologia escolar como campo de atuação; percepções dos profissionais acerca do referencial teórico utilizado para orientar a prática profissional; percepção do trabalho dos psicólogos pela comunidade escolar; percepções dos profissionais sobre as situações em que o trabalho é mais solicitado, e as atividades desenvolvidas nas escolas pelos psicólogos. Os dados que emergiram das entrevistas foram discutidos à luz de reflexões de autores e pesquisas na área.

Vale ainda mencionar que esta pesquisa foi submetida ao Comitê de Ética em Pesquisa da Universidade Estadual da Paraíba (UEPB), obtendo aprovação por meio do protocolo de número CAAE 0176.0.133.000-09.

\section{Resultados e discussóes}

Em relação aos dados referentes aos motivos que levaram os profissionais a optar pela área de psicologia escolar como campo de atuação, os entrevistados referiram que "acham uma área importante" (4); "pela oportunidade de trabalho na área" (2) e "pela curiosidade de conbecer a área de atuação" (1). Observa-se que a maioria dos profissionais (quatro psicólogos) reconhece a importância da área de psicologia escolar, o que pode indicar um fator importante para atuação.

No que concerne às percepções dos profissionais acerca do referencial teórico utilizado para orientar a prática profissional, identificou-se três categorias de respostas, quais sejam: "utiliza uma abordagem teórica para orientar a prática profissional” (3); "utiliza duas ou mais abordagens teóricas para orientar a prática" (3) e "não utiliza abordagem" (1).

Pôde-se verificar que três profissionais utilizam duas ou mais abordagens e três citaram apenas uma. As abordagens teóricas citadas foram: a Abordagem Humanista (três profissionais), a Abordagem Sociointeracionista (três profissionais), e a Abordagem Psicanalítica (três profissionais).

Apenas um sujeito da amostra não utiliza abordagem ou referencial teórico, justificando essa escolha afirmando ter uma carga horária extensa, o que não lhe permite refletir sobre a teoria, tal como se segue: "o que en sempre ouvi falar, e que é verdade, é que na prática que somos obrigados a formular uma própria teoria. Porque como é muito dinâmico não dar tempo você (sic) parar e pensa (sic) tal coisa". Sobre esse aspecto, Correia (2004) afirma ser primordial o embasamento teórico para prática do profissional de psicologia no contexto educacional. Ao mesmo tempo, a autora critica posturas que "psicologizam" o fazer psicológico, ou seja, posturas que focam apenas nos aspectos afetivos e emocionais, uma vez que contribuições diante do processo educativo são mais relevantes para o contexto educativo.

Ainda com relação a esses resultados, observou-se que as teorias citadas pelos profissionais como aquelas que embasam suas práticas parecem desarticuladas entre psicologia e educação, sendo pouco observadas no discurso desses profissionais teorias que subsidiem as práticas focadas na educação. Verificou-se que mesmo os profissionais que trabalham referendados por teóricos como Piaget e Vygotsky, que em suas teorias trazem contribuições relevantes para questões referentes ao processo educativo, mostram pouca preocupação em articular as problemáticas do cotidiano escolar, evidenciando questões mais focadas no aluno, conferindo uma visão de diagnóstico e ajustamento desse aluno. Exemplificam esse dado as falas dos psicólogos 1 e 2.

Psicólogo 1: "eu utilizo vários autores teóricos para que minhaprática tenha resultadospositivos, satisfatórios. Então uso instrumentos e técnicas psicológicas para contribuir com o ajustamento psicológico do educando".

Psicólogo 2: "não dá para você trabalhar, fazer psicologia educacional isenta de um olhar clínico... quer queira ou não, em qualquer que seja a área eu trabalho com o sintoma, e o sintoma não é aquele que me aparece só, tem algo que está oculto, então eu tenho que ter um olhar clínico".

A análise dessas questões pode demonstrar que os psicólogos entrevistados não parecem estar instrumentalizados teoricamente para trabalhar de maneira satisfatória na instituição escolar e romper com formas tradicionais de atuação. Essa questão é discutida por autores que falam sobre as dificuldades encontradas na prática do psicólogo escolar, tal como Almeida (2002), que discute essa dissociação existente entre teoria e prática. Para a autora, muitos psicólogos acabam não tendo clareza suficiente sobre os determinantes filosófico-ideológicos das teorias psicológicas e, por consequência, acabam adotando 
intervenções contrárias ao referencial teórico que dizem seguir. Sendo assim, considera-se a necessidade de superar práticas que não tenham o respaldo teórico, e ainda procurar estabelecer relações entre a psicologia e o campo educativo. Quanto à percepção do trabalho dos psicólogos pela comunidade escolar, identificaram-se as seguintes respostas: "umprofissional que lida com patologias e com situações de emergência" (6); "um clinico na escola"(2); "um solucionadorosproblemas"(2) e "mágico e feiticeiro" (2). Verifica-se, portanto, que as respostas de alguns profissionais inserem-se em mais de uma categoria de resposta. Pode-se observar que houve predominância (seis profissionais) no aspecto "lidar com patologias e situações de emergência" como característica principal da ação do psicólogo na escola.

No que tange à percepção do psicólogo enquanto solucionador de problemas, ilustram o dado as falas dos psicólogos 1 e 6 :

Psicólogo 1: "quando cheguei em uma das escolas, fui abordada por uma professora que disse: graças a Deus chegon a psicóloga que vai resolver os problemas desses meninos"

Psicóloga 6: "ainda existe aquela imagem de que o psicólogo é o mágico, de que o psicólogo vai dar uma resposta imediata. Existe essa representação social, ainda, de que o psicólogo vem pra atender de imediato os problemas que surgem".

As considerações sobre o psicólogo como um clínico foram citadas por dois profissionais, o que talvez indique uma confusão que a comunidade escolar faz entre a atuação do psicólogo clínico e do psicólogo escolar. Ilustra esse dado a fala do Psicólogo 5 , que ressaltou a dificuldade de diferenciar a atuação do psicólogo clínico e do psicólogo escolar.

Psicólogo 5: "eu acho que hoje ainda eles veem a gente com a visão de clínica na escola. É difícil fazer a diferença". Além do mais, um profissional disse que a visão deturpada do psicólogo dificulta seu trabalho na escola, como ilustrado nesta fala: "a gente tenta montar projeto, até alguns projetos eu já desenvolvi, mas você percebe que eles querem muito resolver o problema naquele momento" (Psicólogo 5).

Um profissional reconheceu que existem limitações para mudar a percepção da comunidade escolar sobre o papel do psicólogo. Segundo ele: "infelizmente a gente não tem muitas oportunidades para tirar este estigma de mágico, daquela pessoa que não erra, daquela pessoa que sempre tem uma solução pra tudo" (Psicólogo 7).
Para os sujeitos da amostra o papel do psicólogo na escola não está bem definido, pois a comunidade escolar tem a percepção do profissional como alguém que pode dar conta dos problemas existentes no aluno. E, de certa forma, o próprio profissional tem participação nisso, de modo que, na maioria das vezes, nem para ele está claro o seu papel, o que se torna um entrave para efetivar sua atuação.

Esses dados demonstram uma realidade conhecida por autores da área (Guzzo, 1996; Correia, 2004) que discutem o perfil do psicólogo escolar. Guzzo (1996) reconhece que não existe ainda no país uma especificidade no título profissional, ou seja, não existe um modelo de atuação difundido e estudado, o que dificulta uma prática competente no contexto educacional e alarga a fragilidade desse profissional. Correia (2004), ao analisar a estrutura de inserção do psicólogo na escola, aponta algumas dificuldades encontradas para a prática do psicólogo no cenário educacional. Para ela, o conhecimento ou o "não conhecimento" da profissão pela comunidade escolar é considerado um grande desafio para atuação do psicólogo. De acordo com a autora, um grande desafio para o psicólogo escolar é o de se fazer reconhecer pela comunidade escolar como detentor de contribuições relevantes para agir como mediador do processo educativo (Correia, 2004). No entanto, esse desafio só poderá ser alcançado à medida que os profissionais se firmarem nesse processo.

No que tange às percepções dos profissionais sobre as situações em que o trabalho é mais solicitado, as categorias de respostas foram divididas da seguinte forma: "cobrança de atendimento em situações de emergência, tais como problemas de aprendizagem e de comportamento" (Psicólogo 6); e "na mediação de conflitos entre os profissionais da escola ou entre professor-aluno" (Psicólogo 3).

Percebe-se que, para a maioria dos sujeitos participantes da pesquisa, o psicólogo escolaré mais solicitado a intervir em situação de emergência e na mediação de conflitos ocorridos na instituição. O psicólogo na escola é muito solicitado para atender a "criançaproblema", e cobra-se uma resposta imediata do profissional. Exemplificam esse dado as falas dos psicólogos 4, 5 e 7, quando afirmam:

Psicólogo 4: "o psicólogo é mais solicitado nos eventos que estremecem... Nós somos solicitados a intervir como se tivéssemos uma vara de condão para aquele evento". 
Psicólogo 5: “somos solicitados em relação àcriança problema, criança com problema de comportamento. É um pouco um bombeiro. Se tem criança com problema, a criança que está dando problema, então procura o psicólogo na escola".

Psicólogo 7: "sou mais solicitada quando existe um quadro conflituoso [...] conflitos de relações interpessoais".

Para Leite \& Valle (2003, p. 23), o psicólogo escolar luta pela compreensão social de sua função e esbarra em dois desafios, quais sejam: afirmar-se em seu espaço de trabalho, ou seja, incluir-se na escola de forma que seu "trabalho não termine distorcido ou limitado no campo competitivo que envolve a afirmação de papéis de poder"; e desenvolver sua atuação preventiva, não apenas remediativa ou voltada para clínica, devendo envolver escola e família.

Além do mais, um profissional salientou o fato dos próprios profissionais de psicologia não saberem qual seu papel na escola. A Psicóloga 5, ao referir-se à tentativa de montar um documento quando começou atuar na instituição de ensino, em que junto a outras profissionais da área estudava o papel do psicólogo escolar, mencionou a dificuldade doprofissional reconbecer sua especificidade dentro da instituição. Referindo-se a esse aspecto relatou: "é muito difícil, talvez a gente não tenha internalizado isso muito bem ainda". O fato dos próprios profissionais ainda não terem claras suas funções na instituição revela um problema ainda maior, pois esse fato faz com que os profissionais adotem práticas que reproduzem os aspectos solicitados pela comunidade escolar, atuando, necessariamente, em situações de emergência que ocorrem nas escolas.

Em relação às atividades desenvolvidas nas escolas pelos psicólogos, identificaram-se as seguintes respostas: "trabalho com os professores" (4); "trabalho com as famílias" (3); "mediação das relações interpessoais" (3); "encaminhamento de criancas a outros profissionais on instituiçôes especializadas" (3); "escuta individual" (2); "visita domiciliar" (1); "psicoterapia de grupo" (1); "psicoterapia breve (1)". Destaca-se que na categoria trabalho com professores foram citadas as seguintes atividades: desenvolvimento de atividades em sala de aula (dois profissionais) e atendimento em sala de recurso (um profissional).

Quatro profissionais citaram trabalhosjunto aos professores, sendo as intervenções discutidas no planejamento pedagógico. As falas dos psicólogos 1 e 5 exemplificam como se dar esse trabalho e sua importância.

Psicólogo 1: "no planejamento a gente assessora e orienta o professor no processo ensino-aprendizagem”.
Psicólogo 5: "a gente contribui com o conhecimento da psicologia para mediar com os professores como se dá o processo de construção de conbecimento e favorecer o processo".

O Psicólogo 2, ao falar do seu trabalho junto aos professores, destaca a dificuldade que encontra no desenvolvimento desse trabalho; ele argumentou que os professores incomodam-se ao serem instigados a repensar sua prática; segundo ele: "os professores veem o psicólogo como alguém que vai fazer repensar a prática e isso incomoda. Eles não querem repensar a prática".

Três profissionais mencionaram trabalhos desenvolvidos com as famílias. Estes acontecem, necessariamente, junto aos projetos desenvolvidos na escola e em reuniões de pais. Os projetos desenvolvidos com as famílias foram os seguintes: família na escola, SOS ambiente e violência.

Quanto à mediação das relações interpessoais, citada por três profissionais, as intervenções são realizadas quando ocorrem conflitos, quer seja entre professor-professor ou professor-aluno ou com funcionários. A abordagem utilizada pelo profissional 1 é a sensibilização do professor por meio do diálogo. O profissional 3 justifica sua intervenção nas relações interpessoais com os professores como importante no processo ensino-aprendizagem. Para ele, "uma coisa que falta para o professor, além da questão pedagógica, é a questão das relações interpessoais. Então procuro trabalhar nesse foco".

Em relação ao encaminhamento de crianças a outros serviços, esses encaminhamentos são feitos a instituições especializadas, como Centro de Atenção Psicossocial (CAPS) e Centro Assistencial de Criança Excepcional (CACE) ou a outros profissionais como Psiquiatra ou Psicólogo Clínico.

$\mathrm{Na}$ caracterização das intervenções profissionais, pôde-se perceber que a maioria dos sujeitos reconhece a importância de um trabalho interdisciplinar. Seis dos sete psicólogos da amostra disseram procurar a efetivação de ações com a equipe multiprofissional. Essa equipe é composta por um psicólogo, um assistente social, um orientador e um supervisor educacional. Quatro psicólogos trabalham com projetos desenvolvidos com a equipe. Os projetos citados pelos profissionais foram os seguintes: paz nas escolas, família na escola, violência, amor, drogas, sexualidade, SOS ambiente e educação inclusiva.

O trabalho interdisciplinar refere-se a trocas de conhecimentos entre a psicologia e a pedagogia. Isso ficou claro na fala do Profissional 3: “'boje eu tenho 
um apoio pedagógico com a supervisora, ela lança mão dos seus conhecimentos pedagógicos e isso tem me ajudado muito".

Segundo os psicólogos entrevistados, o trabalho com os outros profissionais é desenvolvido também no planejamento pedagógico, elaborando projetos e em atividades com ao professor. Dois profissionais (1 e 5) falaram do trabalho com a equipe na avaliação social e familiar dos alunos. Exemplifica esse dado o seguinte trecho da fala do profissional 1: "eu procuro trabalhar dentro da equipe multiprofissional, trabalho muito com a assistente social, que analisa muito os critérios sociais, a história de vida de cada aluno, o contexto familiar. E, baseado nisso, a gente trabalha na perspectiva de melhorar esse desenvolvimento tanto na sala de aula como na própria família".

Na fala do Psicólogo 5, pode-se observar que existe interação e diálogo entre os profissionais, quando eles discutem sobre as intervenções para as situações presentes. Segundo o entrevistado relata:

na minha atuação eu sempre procurei trabalhar junto com a equipe, então a gente faz a leitura da escola, um diagnóstico de como é a estrutura daquela escola, se a questão enfoca comportamento, aprendizagem. Então eu tento junto com a equipe ver que estratégias a gente pode utilizar para contribuir naquele momento.

Já na fala do Psicólogo 4 não fica explícito se existe diálogo entre os profissionais. Ele parece fazer uma associação entre interdisciplinaridade e atividade em grupo "as atividades que a gente desenvolve, como somos uma equipe multidisciplinar, são atividades mais em conjunto. A visita domiciliar é onde eu me encanto mais".

A troca de conhecimentos com outras áreas é vista positivamente por autores que discutem sobre a atuação do psicólogo escolar, pois o trabalho na escola passa, necessariamente, pela necessidade de um trabalho interdisciplinar que envolva à comunicação entre pedagogia e psicologia. Sobre essa comunicação, Santos (2004, p. 93), referindo-se à atuação do psicólogo, ressalta que "seria impossível para ele cumprir sua função de educador, sem considerar toda relação entre as ciências afins com a psicologia e a sub-áreas da mesma". Compreender essa relação é primordial para atuar na escola de forma eficaz, visto que a "a atuação do psicólogo se dá nas e através das interações sociais". No entanto, Santos (2004,p. 89), ao fazer uma análise crítica de interdisciplinaridade, destaca que "O fato de se admitir a existência de parceria não implica afirmar que há necessariamente interdisciplinaridade, e consequentemente redenção do pensamento e do conhecimento", dessa forma considera o diálogo como característica básica da interdisciplinaridade.

Percebeu-se, ainda, por meio das análises das falas dos profissionais, que a atuação do Psicólogo na escola ainda encontra-se centrada no aluno. Cinco profissionais deixam clara essa visão de foco no aluno. Exemplifica o dado a fala do Psicólogo 2: "a escola é depositária da sociedade e da família, a sintomatização da criança passa pela escola. Todo aluno traz um sintoma e, quer queira ou não, esse sintoma é detectado na escola". Vemos também nesse trecho uma grande ênfase na doença. Andrada (2005, p. 197) discute sobre essa questão, e afirma que "a visão de muitos profissionais da educação ainda está pautada no paradigma de normalidade $\mathrm{x}$ anormalidade, onde se espera um padrão de comportamento e de atitudes que condizem com o sucesso".

Em geral, percebe-se que há uma ampliação no discurso sobre o campo de atuação do psicólogo na escola, o qual se refere à elaboração de atividades diversificadas envolvendo professores, alunos e família. Algumas atividades desenvolvidas parecem superar o modelo médico e individualista já criticado por vários autores, como Novaes (1996); Leite e Valle (2003), dentre outros.

\section{Consideraçóes finais}

Os resultados obtidos neste estudo demonstram que os psicólogos entrevistados concebem suas atividades como diversificadas. O trabalho interdisciplinar foi destacado pelos psicólogos como importante para a prática profissional, bem como o desenvolvimento de atividades integrando aluno, professores e família. No entanto, vale destacar a desarticulação existente entre teoria e prática profissional, que pode ser observada pelo distanciamento entre o que os psicólogos relatam como sendo seu papel, e a sua prática profissional. O fato de apenas dois psicólogos terem formação na área escolar educacional revela-se como forte implicação para uma prática desarticulada da teoria.

O conjunto dos resultados obtidos sugere a existência de dificuldades com as quais os psicólogos se deparam em sua prática, em especial, as deficiências existentes na formação profissional, fortemente influenciada pela formação na área clínica. 
A opção por essa área de supervisão foi escolhida por quatro profissionais, o que leva-nos a outras questões que dizem respeito a uma fundamentação teórica distanciada daquela que seria necessária para trabalhar de maneira satisfatória na escola: a falta de compreensão da comunidade escolar acerca do seu papel na escola e a manutenção de práticas que centram o "problema" no aluno.

Com base na análise dos dados pode-se perceber que a área de psicologia escolar ainda não consolidou a sua identidade profissional. Isso fica evidente nas concepções dos psicólogos acerca de sua atuação nas escolas, já que para eles a comunidade escolar tem uma visão equivocada de seu trabalho.

A crise de identidade que atinge o psicólogo escolar pode ser superada incluindo a diversificação de práticas que visam à aprendizagem escolar, buscando um encontro entre psicologia e educação. A atuação do psicólogo no âmbito escolar é de fundamental importância, e sua atuação diante do processo educativo constitui uma de suas formas de intervenção. Faz-se necessária uma atuação contextualizada, na qual a psicologia possa mostrar suas contribuições no campo educativo. Essa ideia ganha apoio em pesquisas na área que consideram que a prática em psicologia escolar atual exige uma práxis contextualizada e uma compreensão dialética da relação entre indivíduos, enquanto sujeito de sua história, e o contexto sociocultural (Almeida, 2002; Almeida \& Marinho-Araújo, 2005; Santos, 2004).

Entende-se que um grande desafio para o psicólogo é o de se fazer reconhecer pela comunidade escolar como detentor de contribuições relevantes para agir como mediador do processo educativo, tal como propôs Correia (2004). No entanto, esse desafio só poderá ser superado à medida que os profissionais se firmarem nesse processo e conhecerem melhor suas possibilidades de atuação para demonstrá-las à comunidade escolar e ressignificar sua atuação profissional.

A partir dos resultados obtidos nessa pesquisa, sugere-se que outros estudos possam ser realizados, pois muitas indagações ainda permeiam esse campo de conhecimento. Propõe-se que futuros estudos utilizem um maior número de participantes, incluindo psicólogos de escolas públicas e privadas, na perspectiva de caracterizar e melhor conhecer as realidades e formas de atuações desses profissionais em seus contextos de atuação.
É relevante o desenvolvimento de pesquisas em torno de questões referentes à área da psicologia escolar, abordando tanto a atuação como a formação dos profissionais, bem como questões referentes à consolidação da identidade profissional e o seu espaço de atuação.

\section{Referências}

Almeida, S. F. (2002). O psicólogo no cotidiano da escola: Re-significando a atuação profissional. In R. S. Guzzo. Psicologia escolar: LDB e educação hoje (pp. 77-89). Campinas: Alínea.

Almeida, S. F., \& Neves, M. M. B. (2003). A atuação da Psicologia Escolar no atendimento dos alunos encaminhados com queixas escolares. In S. F. Almeida (Org.). Psicologia Escolar: Ética e competência na formação e atuação profissional (pp. 83-103). Campinas: Alínea.

Almeida, S. F., \& Marinho-Araújo, C. M. (2005). Psicologia Escolar: Construção e consolidação da identidade profissional. Campinas: Alínea.

Andrada, E. G. (2005). Novos paradigmas na prática do psicólogo escolar. Psicologia: Reflexão e Crítica, 18 (2), 196-199.

Correia, M. (2004). O desafio do cenário escolar para o profissional da psicologia: Por onde começar? In M. Correia (Org.). Psicologia e escola: Uma parceria necessária (pp. 61-82). Campina: Alínea.

Guzzo, R. S. (1996). Formando psicólogos escolares no Brasil, dificuldades e perspectivas. In S. M. Wechsler (Org.). Psicologia escolar: Pesquisa, formação e prática (pp. 75-89). Campinas: Alínea.

Leite, L., \& Valle, R. (2003). Psicologia escolar: Um duplo desafio. Psicologia Ciência e profissão, 23 (1), 22-29.

Martins, J. B. (2003). A atuação do psicólogo escolar multirreferencialidade, implicação e escuta clínica. Psicologia em Estudo, 8(2), 39-45.

Martinez, A. M. (2003). O psicólogo na construção da proposta pedagógica da escola: áreas de atuação e desafios para formação. In S. F. Almeida (Org.). Psicologia escolar: Ética e competência na formação e atuação profissional (pp. 105- 123). Campinas: Alínea. 
Novaes, M. H. (1996). Perspectivas para o futuro da psicologia escola. In S. M. Weschler. (Org.). Psicologia escolar: Pesquisa, formação e prática (pp. 105-123). Campinas: Alínea

Reis, C. S., Menezes, C. L. de, Carvalho, K. C., Ataíde, P. C. Q. de, Belfort, S. F., \& Cassote, S. B. Mitos e verdades sobre a atuação do psicólogo escolar: A visão deste pelos profissionais e alunos de uma instituição de ensino privada em Manaus. Recuperado em 30 de set. de 2008, em http:/ /www. psicologia.com.pt.

Santos, C. S. (2004). A atuação do psicólogo escola/educacional e habilidades sociais: uma relação necessária. In M. Correia. (Org.). Psicologia e escola: Uma parceria necessária (pp. 83-100). Campinas: Alínea.

Tanamachi, E. R., \& Meira, M. E. (2003). Atuação do psicólogo como expressão do pensamento crítico em psicologia e educação. In M. E. Melillo \& M. A. Antunes. (Org.). Psicologia escolar: Práticas críticas. (pp. 11- 62). São Paulo: Casa do Psicólogo.

Recebido: $13 / 04 / 2010$

Received: 04/13/2010

Aprovado: 21/09/2010

Approved: 09/21/2010 